\title{
Padrões de canal do rio Paraguai na região de Cáceres (MT)
}

\author{
Aguinaldo Silva', Edvard Elias de Souza Filho ${ }^{2}$ \& Sandra Baptista da Cunha ${ }^{3}$
}

\begin{abstract}
Resumo A bacia do alto rio Paraguai vem passando por um intenso processo de ocupação agrícola. A ocupação das vertentes, a navegação fluvial e uma possível tectônica ativa são fatores que podem levar à modificação do sistema fluvial. Uma vez que o segmento fluvial estudado está situado a montante do Pantanal Mato-Grossense, as modificações que o afetarem podem vir a ter influência na referida bacia de acumulação. O objetivo deste trabalho é caracterizar o padrão de canal do segmento do rio Paraguai situado entre o rio Cabaçal e o morro Pelado, na região de Cáceres (MT), como forma de entender sua dinâmica e poder colaborar com informações que auxiliem a tomada de decisão a respeito do planejamento de uso do solo e do rio, na área. Para isso, foi realizada a caracterização morfológica e dinâmica do canal e da planície, por meio de uso de imagens orbitais, de dados de estações fluviométricas, e trabalho de campo. A análise do segmento fluvial estudado demonstrou que o canal possui dois segmentos com diferentes padrões. O segmento superior apresenta características de canais meandrantes e entrelaçados, enquanto o segmento inferior possui características de canais retilíneos, e entrelaçados, com sua planície com formas típicas de sistema anastomosado. Tal situação indica que todo o segmento está em processo de ajuste fluvial, desencadeado por provável aumento no aporte de sedimentos arenosos.
\end{abstract}

Palavras-chave: padrões de canal, ajuste fluvial, rio Paraguai Superior.

\begin{abstract}
The channel patterns of the Paraguay river on the Cáceres area (MT). The aim of this study is to characterize the channel pattern of the Paraguay River between Cabaçal River and Pelado Hill in the Cáceres area (MT). To do so, analyses on the fluvial hydrodynamics, on the morphology of the channel and the floodplain, and on the typology of the fluvial bars, were carried out. The research was developed through the use of the orbital images, hydrologic data and field works. The morphologic analysis, the floodplain landscapes, and the fluvial bars styles showed that such channel presents two segments with different patterns. The upper segment has meandering and braided characteristics and the lower segment has straight and braided channel characteristics and anastomosed forms on their floodplain. The occurrence of different channel pattern characteristics on the studied fluvial segment indicates that the fluvial system is currently in adjustment process, as a result of excessive sandy sediments input.
\end{abstract}

Keywords: channel pattern, fluvial adjustment, High Paraguay River.

INTRODUÇÃOO O rio Paraguai tem suas nascentes no planalto dos Parecis no Estado do Mato Grosso. Fluindo de norte para sul, o rio percorre uma extensão de $2.621 \mathrm{~km}$, dos quais $1693 \mathrm{~km}$ em território brasileriro, até sua confluência com o rio Paraná na altura da cidade de Corrientes, na Argentina (INNOCENCIO 1977). Sua bacia de drenagem totaliza $1.095 .000 \mathrm{~km}^{2}$, compreende os estados de Mato Grosso e Mato Grosso do Sul e parte dos territórios da Bolívia, do Paraguai e da Argentina (ANA 2004). De acordo com IBGE (1977), o rio Paraguai Superior é o segmento compreendido entre as suas nascentes e a foz do rio Jauru, enquanto o Alto Paraguai compreende o trecho entre o rio Jauru e a foz do rio Apa, que abrange toda a área do Pantanal Mato-Grossense.

A parte superior do Alto Paraguai, especificamente o intervalo entre a foz do rio Jauru e a Boca do Bracinho, é um segmento fluvial em que o canal e a pla- nície fluvial encontram-se bem definidos, à semelhança do Paraguai Superior, enquanto que o restante do curso do Alto Paraguai desenvolve-se na área do Pantanal. Por essa razão, todo o trecho a montante da Boca do Bracinho será aqui considerado como Paraguai Superior.

Os estudos relativos ao rio Paraguai Superior escassos e em sua maior parte a abordagem é regional, como é o caso do RADAMBRASIL (1982) e do Plano de Conservação da Bacia do Alto Paraguai-Pantanal (PCBAP 1997). Alem desses, Souza (2004) e Silva (2006 2007) realizaram estudos a respeito da geomorfologia fluvial do segmento entre Cáceres e a Estação de Taimã.

A região do rio Paraguai Superior passa por transformações econômicas em decorrência da pecuária, do turismo e da implantação da hidrovia ParaguaiParaná. A intensificação da pecuária tem provocado

\footnotetext{
1- Programa de Pós-Graduação em Geociências e Meio Ambiente, Instituto de Geociências e Ciências Exatas-IGCE, Universidade Estadual Paulista, Rio Claro (SP), Brasil. E-mail: aguinald_silva@yahoo.com.br

2- Universidade Estadual de Maringá (UEM), CCH, DGE/GEMA, Maringá (PR), Brasil. E-mail: edvardmarilia@wnet.com.br

3- Universidade Federal Fluminense (UFF), Instituto de Geociências, Departamento Geografia, Boa Viagem, Niterói (RJ), Brasil.

E-mail: sandracunha@openlink.com.br
} 
modificações no uso do solo na bacia, na medida em que substitui a vegetação natural por pastagens. $\mathrm{O}$ incremento do turismo contribui para o aumento do uso de embarcações rápidas no rio e o transporte de produtos agrícolas por via fluvial tem exigido a dragagem de vários pontos do canal.

As modificações do uso do solo das vertentes podem alterar o aporte de sedimentos no sistema, as embarcações rápidas aumentam a incidência de ondas no canal e a implantação da hidrovia pode vir a modificar parte das características do rio. O problema fundamental é que tais modificações estão sendo feitas sem um conhecimento adequado do sistema fluvial, e conseqüentemente, sem um planejamento que permita a minimização dos seus efeitos sobre o rio Paraguai. Tal situação é agravada pelo fato do rio ser um importante contribuinte do Pantanal Mato-Grossense, situado logo à jusante da região.

A importância ambiental do sistema fluvial, as modificações que a bacia de drenagem vem passando, a escassez de informação a respeito das características do rio justificam a realização de estudos que visem ao adequado conhecimento da região e ao levantamento dos problemas que futuramente servirão de base para desenvolvimento sustentado. Justificado por esses aspectos, o objetivo desse trabalho é caracterizar os padrões de canal do rio Paraguai Superior no trecho compreendido entre a foz do rio Cabaçal e o morro Pelado (Fig. 1).

ÁREA DE ESTUDOS Situa-se na região de Cáceres, Estado de Mato Grosso, e compreende o segmento localizado entre a foz do rio Cabaçal e a área do morro Pelado, entre as coordenadas $15^{\circ} 45^{\prime} 00^{\prime \prime}-16^{\circ} 35^{\prime} 00^{\prime \prime}$ de latitude sul e $57^{\circ} 40^{\prime} 00^{\prime \prime}-58^{\circ} 15^{\prime} 00^{\prime}$ " de longitude oeste (Fig. 1).

O clima da região de Cáceres caracteriza-se como Tropical com duas estações bem definidas (seca no inverno e úmida no verão), temperatura média anual de $25^{\circ} \mathrm{C}$ e precipitação média de $1.396 \mathrm{~mm} /$ ano. $\mathrm{O}$ período de janeiro a março é o mais úmido, com média histórica de $200,83 \mathrm{~mm}$ e o período entre setembro e outubro é o de maior índice de radiação solar e de mais baixa precipitação.

$\mathrm{O}$ rio Paraguai Superior possui $432 \mathrm{Km}$ de extensão e sua área de drenagem é pouco maior que $48.450 \mathrm{~km}^{2}$ (DNOS 1974). A bacia de drenagem tem forma assimétrica com os afluentes da margem direita mais longos que os da margem esquerda. Pela margem direita, os principais tributários do rio na área de estudo são Cabaçal e o Jauru (Fig. 1).

A disposição da bacia é condicionada pelo substrato geológico. As nascentes do rio Paraguai estão situadas em área cratônica do Complexo Xingu (PréCambriano Médio a Inferior), o curso principal está situado sobre o limite entre a Zona Externa e a Zona de Plataforma da Faixa Paraguai (Almeida 1964) e ocupa a parte mais baixa de um amplo sinclinal assimétrico com flancos com mergulhos suaves para leste em sua margem direita e com mergulhos acentuados para oeste em sua margem esquerda (Alvarenga \& Trompete 1993).
A faixa ocupada pela calha fluvial é uma sutura com indícios de atividade tectônica (Souza Filho \& Silva, 2005), cortada por linhas estruturais transversais que controlam o curso dos principais afluentes e propiciam a existência de níveis de base locais ao longo do canal principal.

O corredor fluvial delimitado para área de estudo abrange o canal fluvial e a planície inundação do Alto Paraguai. O conjunto constitui um complexo sistema, condicionado pela vasta planície sedimentar com topografia plana, altitudes variando de 90 a 120 metros, sujeita a inundação anual. $\mathrm{Na}$ área da planície de inundação há domínio de solos hidromórficos e está pouco afetada pela ocupação antrópica. Nas partes situadas a montante a planície constitui faixas estreitas, mas torna-se mais ampla para jusante, até confundir-se com as áreas de acumulação do Pantanal.

$\mathrm{Na}$ área de estudo, a calha fluvial pode ser dividida em dois segmentos. O superior situa-se entre Cáceres e a foz do rio Jauru, com $71 \mathrm{~km}$ de extensão, alta sinuosidade, e sua planície de inundação tem largura média de 1700 metros, enquanto o canal alarga-se por 150 metros em média. O canal ocupa a porção central da calha, indicando que as feições superficiais desenvolveram-se sem influência de basculamento tectônico.

O segmento inferior está compreendido entre a foz do rio Jauru e o morro Pelado, possui $35 \mathrm{~km}$ de extensão. O canal possui baixa sinuosidade e $200 \mathrm{~m}$ de largura média. A planície alarga-se por $2900 \mathrm{~m}$ a oeste do canal. A posição relativa do canal indica a existência de basculamento para leste durante ou após a formação da planície. Contudo, os dados de mobilidade recente do canal mostram tendência de migração para oeste, indicando basculamento recente nesta direção (Souza Filho \& Silva, 2005).

Ambos os segmentos apresentam características morfológicas diferentes, uma vez que a sinuosidade, as formas da planície de inundação e as barras fluviais são distintas. Em planta, à primeira vista, o segmento superior pode ser classificado como meandrante, e o inferior como retilíneo. Contudo, ambos apresentam aspectos que não se coadunam com tais classificações, como será discutido à frente.

MÉTODOS As características do canal fluvial, a tipologia das barras e a morfologia da planície definem o padrão do em que elas ocorrem (Fisk 1944, 1947, Leopold e Wolman 1957, Miall 1978, 1985, Selley 1978, Friedman e Sanders 1978, Walker e Cant 1979, Collinson 1986). Portanto, o padrão de canal sintetiza as características da calha fluvial, e permite estabelecer inferências sobre a dinâmica dos processos de erosão e sedimentação, uma vez que as mencionadas características são resultados desses processos, conforme advogado por Kellerhald et al. (1976) e Dietrich (1985).

Assim, os padrões de canal podem ser definidos pelas características morfológicas e dinâmicas do segmento fluvial, conforme apresentado por Miall (1977), Richards (1982), Nanson e Crooke (1992), e Souza Filho (1993). As características morfológicas incluem 


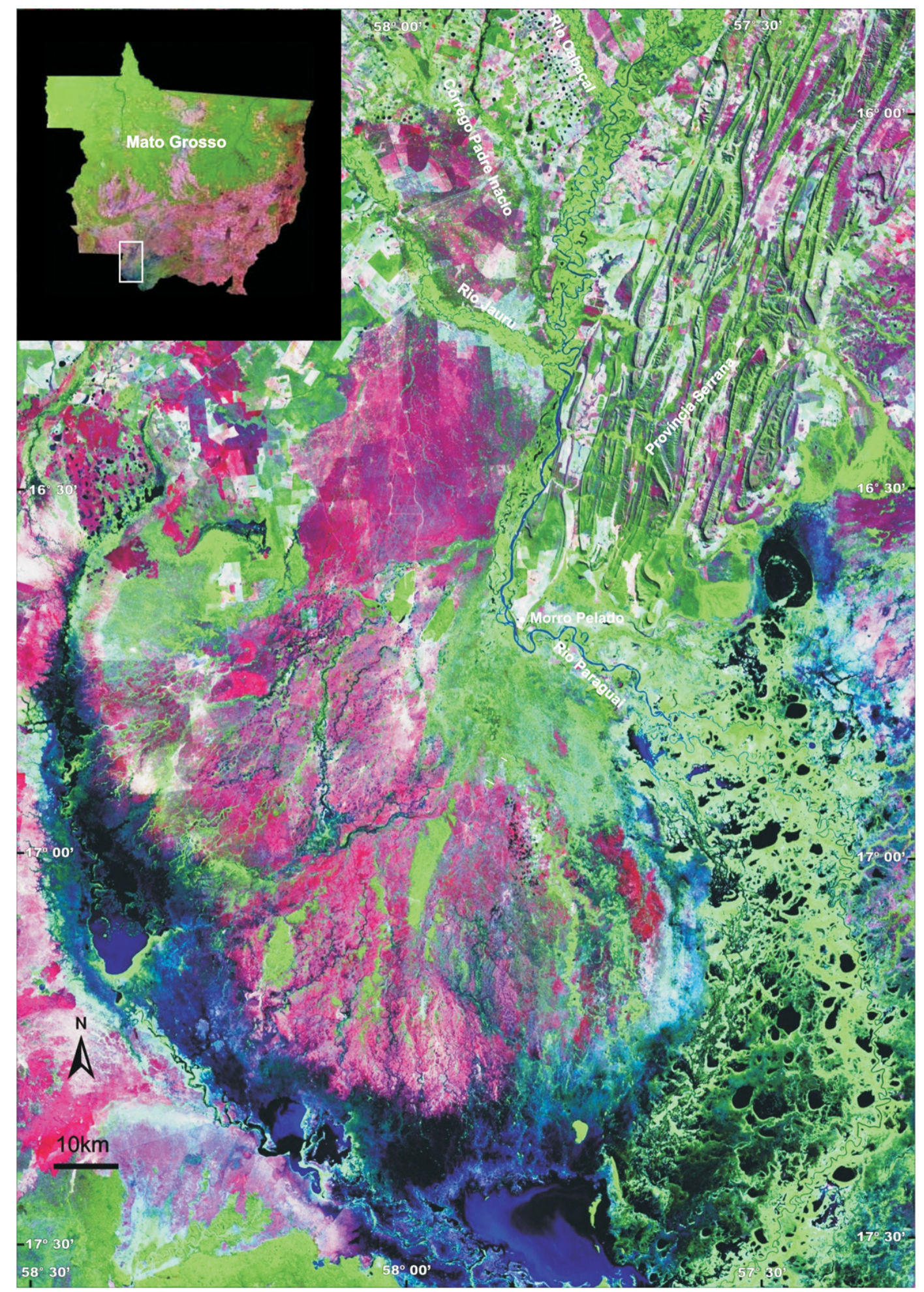

Figura 1 - Imagem de satélite da área estudada em destaque (composição falsa cor RGB 742 com pixel reamostrado para $15 \mathrm{~m}$ a partir da fusão com a banda 8; fonte: NASA Geocover Circas 2000).

tipo de canal (único, multicanal), gradiente do leito, sinuosidade, composição das margens, forma da seção transversal, razão largura/profundidade, tipologia das barras, e características da planície de inundação (tamanho em relação ao canal, formas superficiais, diques marginais). As características dinâmicas incluem velo- cidade de fluxo, potência específica da corrente, mobilidade do canal, e carga de fundo (textura dos sedimentos e razão do transporte de fundo com o transporte total).

As características morfológicas do canal foram obtidas por meio de diversos procedimentos. O tipo de canal por meio de consulta de imagens orbitais (LAND- 
SAT 5 e CBERS 2). O gradiente do leito através do cálculo da diferença de altitude do fundo nas seções de Cáceres e Descalvados, dividido pela distância entre ambas as estações medida ao longo do talvegue. A sinuosidade por meio da divisão da distância entre dois pontos ao longo do talvegue, pela distância entre eles em linha reta.

Os dados sobre a constituição granulométrica das margens, dos diques marginais e do material de leito foram obtidos em trabalho de campo, e a porcentagem de carga de fundo em relação à carga sedimentar foi calculada a partir dos dados de Souza (2004). A forma das seções transversais e a razão largura/profundidade $(\mathrm{L} / \mathrm{P})$ foram elaboradas a partir de mapas batimétricos $\mathrm{e}$ de levantamentos eco-batimétricos.

Os tipos de barras foram classificados por meio de interpretação de imagens, de análise de mapas batimétricos e de levantamentos eco-batimétricos. Por fim, o tamanho da planície, as suas formas superficiais e o desenvolvimento dos diques marginais foram avaliados por meio da interpretação de imagens orbitais. Os procedimentos detalhados estão descritos em Silva (2006).

Os parâmetros dinâmicos do canal são resultado da aplicação dos seguintes procedimentos: a velocidade média nas seções de Cáceres e de Descalvados foi calculada por meio da divisão do valor da descarga de margens plenas pela área da seção molhada no nível hidrológico correspondente. A velocidade máxima foi medida em campo com uso de molinete fluviométrico, em vários pontos dos segmentos fluviais.

A potência específica da corrente foi calculada para a descarga de margens plenas, conforme descrito por Nanson e Crooke (1992), e os procedimentos estão detalhados em Silva (2006). A mobilidade do canal calculada a partir da comparação da posição das margens em imagens de 1984 e 2003, conforme descrito por Silva (2006). Por fim, a relação entre o transporte de fundo e o transporte total a partir dos dados de Souza (2004).

RESULTADOS Dentre o conjunto de dados levantados, o gradiente do leito, o gradiente hidráulico e a potência específica da corrente para o segmento fluvial inteiro, uma vez que as informações necessárias estavam disponíveis apenas para as estações fluviométricas de Cáceres e de Descalvados, situadas respectivamente na parte montante e jusante de todo o compartimento estudado. Os dados de Souza (2004) para os valores de transporte fluvial são referentes à Cáceres, e limitados a 1982. A referida autora calculou a produção específica de sedimentos finos $\left(66 \mathrm{t} / \mathrm{km}^{2} / \mathrm{ano}\right)$ e de sedimentos de fundo $\left(16 \mathrm{t} / \mathrm{km}^{2} / \mathrm{ano}\right)$ da bacia, por meio de dados de transporte fluvial obtidos pela CPRM, o que permitiu verificar que em Cáceres, no ano de 1982, o transporte de fundo correspondia a $19,5 \%$ do transporte total.

$\mathrm{O}$ gradiente médio do talvegue foi de $6,6 \mathrm{~cm} /$ $\mathrm{km}$, resultante da divisão da diferença de cota do fundo em Cáceres (107,35 m) e Descalvados $(98,68 \mathrm{~m})$ pela distância entre ambas as estações $(132 \mathrm{~km})$. O cálculo do gradiente hidráulico efetuado a partir da divisão da diferença de altitude do nível de água entre as duas estações e o comprimento do talvegue principal resul- tou em valores que variaram de $6,8 \mathrm{~cm} / \mathrm{km}$, no caso em que o rio apresentou sua menor vazão na série histórica (133 m³ $/ \mathrm{s}$ em Cáceres), a 9,6 cm/ $/ \mathrm{km}$, em condições de vazão máxima (2659 m³ $/ \mathrm{s}$ em Cáceres). Em vazão de margens plenas, o gradiente hidráulico calculado foi de $7,6 \mathrm{~cm} / \mathrm{km}$, à vazão de $695 \mathrm{~m}$ 3/s.

A potência específica de corrente foi calculada para a vazão de margens plenas em Cáceres e resultou no valor de $1,9 \mathrm{~W} \cdot \mathrm{m}^{2}$, quando foi utilizado o valor de $6,6 \mathrm{~cm} / \mathrm{km}$ para o gradiente do leito, e no valor de 2,2 W. $\mathrm{m}^{2}$, quando utilizado o valor de $7,6 \mathrm{~cm} / \mathrm{km}$. O cálculo foi baseado na premissa de que o leito móvel poderia ter o mesmo gradiente que a lâmina de água.

Segmento superior Conforme mencionado, o segmento superior está compreendido entre Cáceres e a foz do rio Jauru. A análise das imagens referentes a esse segmento demonstra que o rio Paraguai apresenta canal único, com $150 \mathrm{~m}$ de largura média, sinuosidade de 1,7, barras em pontal, e planície bem desenvolvida (com aproximadamente $1700 \mathrm{~m}$ de largura) marcada por meandros abandonados ("oxbow lakes"), canais de avulsão, conforme pode ser observado na figura 2.

A análise das seções transversais levantadas e dos dados batimétricos demonstrou que nos trechos curvos (meandros) o canal é assimétrico, com apenas um talvegue, e com presença sistemática de barra em pontal (perfil 2, figura 3). A menor razão largura/profundidade (L/P) medida foi de 35,2, embora a maior parte dos valores obtidos tenha sido superior a 100. Nos trechos retos (entre meandros), o canal tende a ser simétrico, com fluxo em mais de um talvegue, separados por barras transversais ao canal. A maior razão $\mathrm{L} / \mathrm{P}$ encontrada nos trechos retos foi de 210 , e a menor foi de 115 . O segmento como um todo mostra razão L/P de 126.

Os trabalhos de campo permitiram verificar que as margens do canal são constituídas por lentes de areia fina argilosa, intercaladas em camadas argilosas (Fig. 4, fotografia superior), interpretadas como depósitos distais de diques marginais em meio a sedimentos finos da bacia de inundação. Os diques marginais são pouco desenvolvidos, descontínuos, e são constituídos por lentes de areia fina a média decimétricas, com estratificação sigmoidal. $\mathrm{O}$ aspecto das lentes arenosas que constituem os diques marginais pode ser observado na figura 4 (fotografia inferior). As amostras coletadas no leito do rio demonstraram amplo domínio de areia média (acima de $80 \%$ ).

Segmento inferior No segmento inferior, situado abaixo da foz do rio Jauru, o rio possui canal único com aproximadamente $200 \mathrm{~m}$ de largura, localmente dividido por ilhas, com sinuosidade de 1,2, barras transversais, planície bem desenvolvida (2900 $\mathrm{m}$ de largura média), com lagoas alongadas e depósitos em formas de leque ("crevasse splay"). A figura 5 ilustra as feições mencionadas.

As seções transversais levantadas (Fig. 6) demonstraram que o canal possui seção transversal simétrica, com margens bem definidas, e barras transversais dividindo o fluxo em mais de um talvegue. As relações 


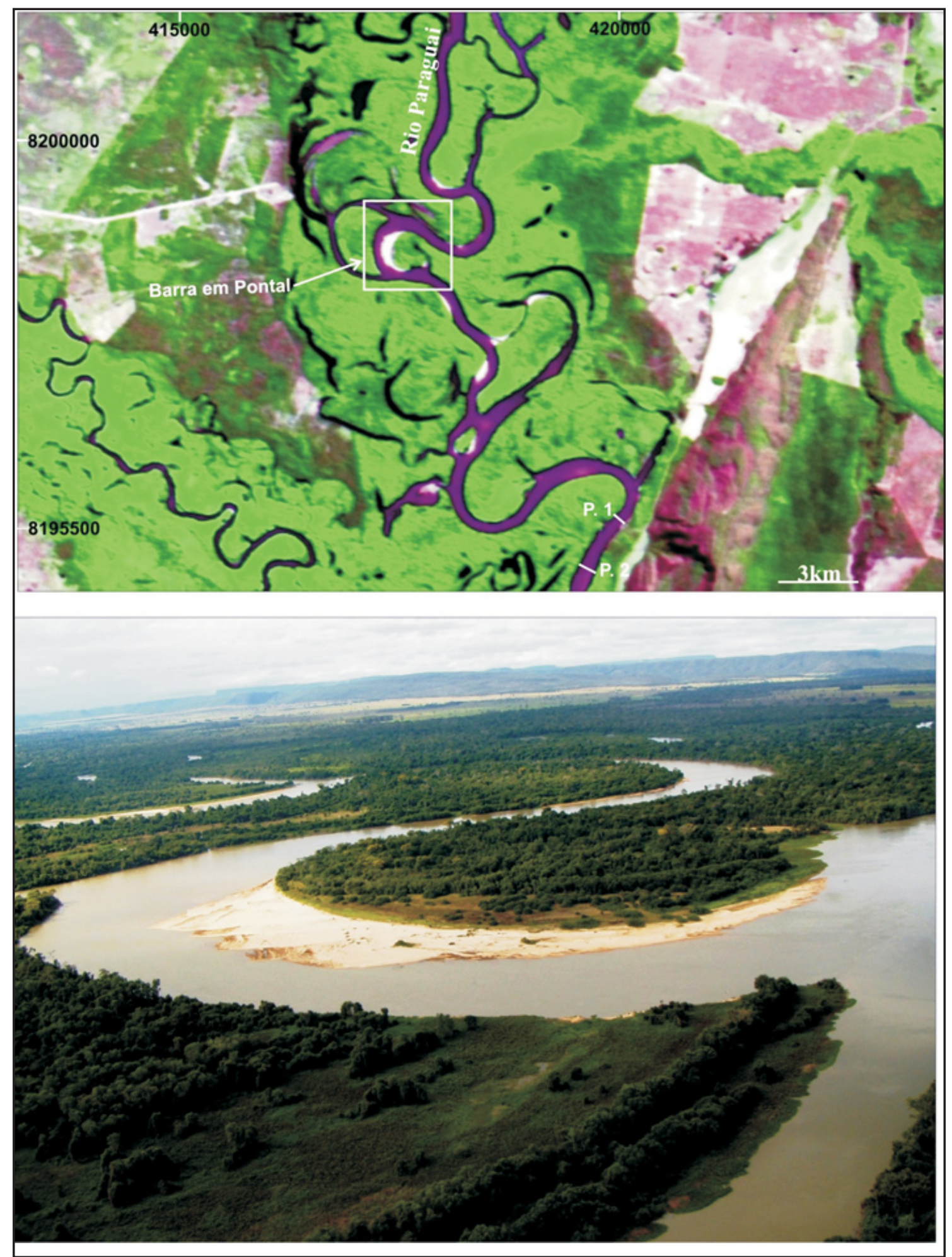

Figura 2 - Imagem de parte do segmento superior e foto da barra em pontal com destaque na imagem.

largura/profundidade (L/P) obtidas variam de 81,9 a 270,7, e a razão média calculada foi de 153.

As margens do canal são predominantemente argilosas (depósitos de bacia de inundação), às vezes com a parte superior formada por argila arenosa (depósitos distais de diques marginais ou de crevasse splay) conforme ilustrado na figura 7. As partes mais altas possuem o mesmo nível altimétrico da planície fluvial, indicando a ausência ou o desenvolvimento incipiente de diques marginais. Os sedimentos coletados no canal apresentaram domínio de areia média (entre 60 e $70 \%$ ), e secundariamente areia grossa (entre 10 e $25 \%$ ). 

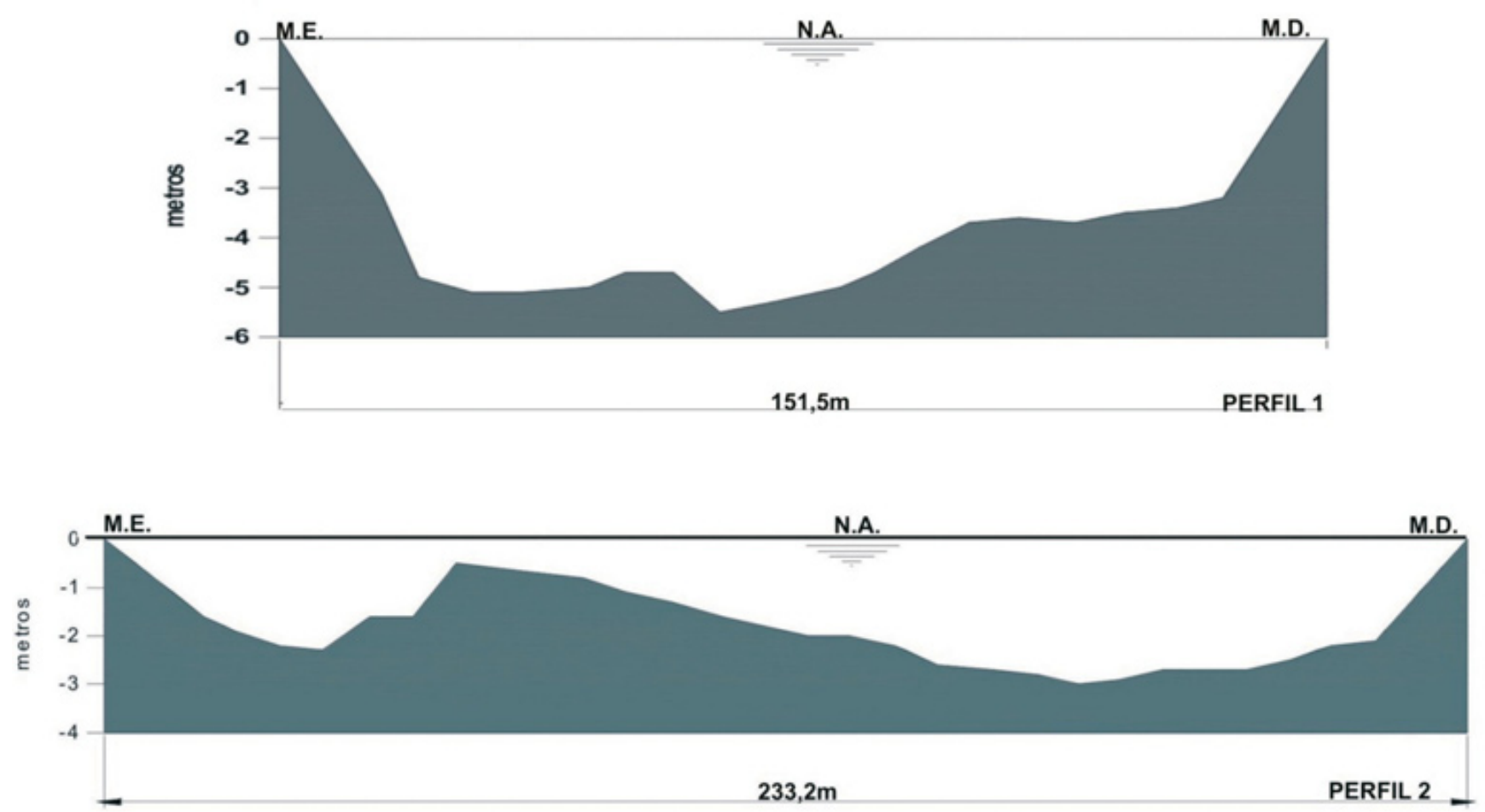

Figura 3 - Exemplos de seções transversais do segmento superior. O perfil 1 está situado a $60 \mathrm{~km}$ da cidade de Cáceres e possui L/P de 35,2.O perfil 2 encontra-se a 62,1 km de Cáceres e possui L/P de 123,8.
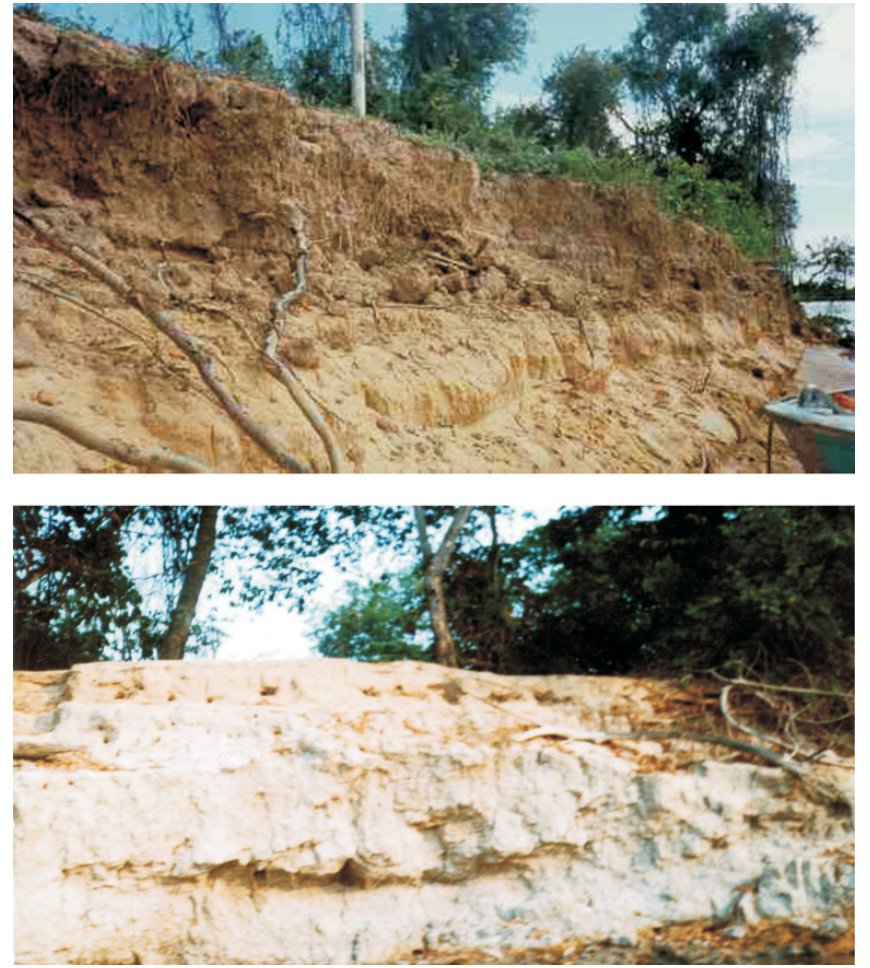

Figura 4 - Fotografias de margens do segmento superior. A fotografia superior mostra intercalação de lentes arenosas em camadas argilosas, e a fotografia inferior mostra lentes arenosas decimétricas de depósitos de dique marginal.

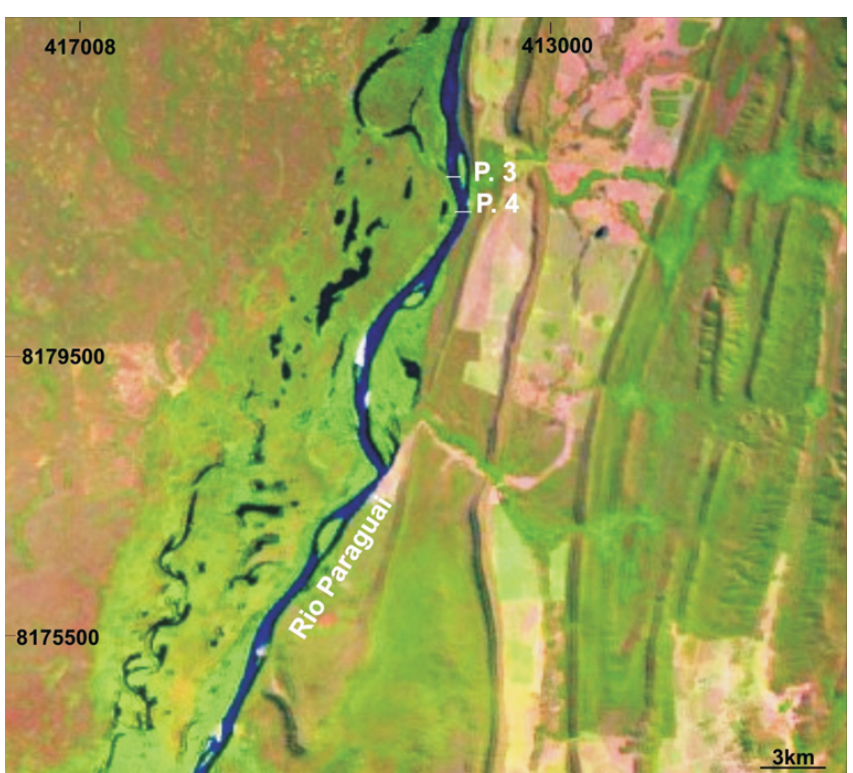

Figura 5 - Imagem da parte montante do segmento inferior.

DISCUSSÃO As propostas de classificação de padrão de canal de rios deposicionais possuem um longo histórico, desde que Fisk (1944) e Leopold \& Wolman (1957) publicaram os trabalhos pioneiros a esse respeito. Dentre essas propostas, há inúmeras classificações diferentes, mas os padrões básicos (entrelaçado, me- 

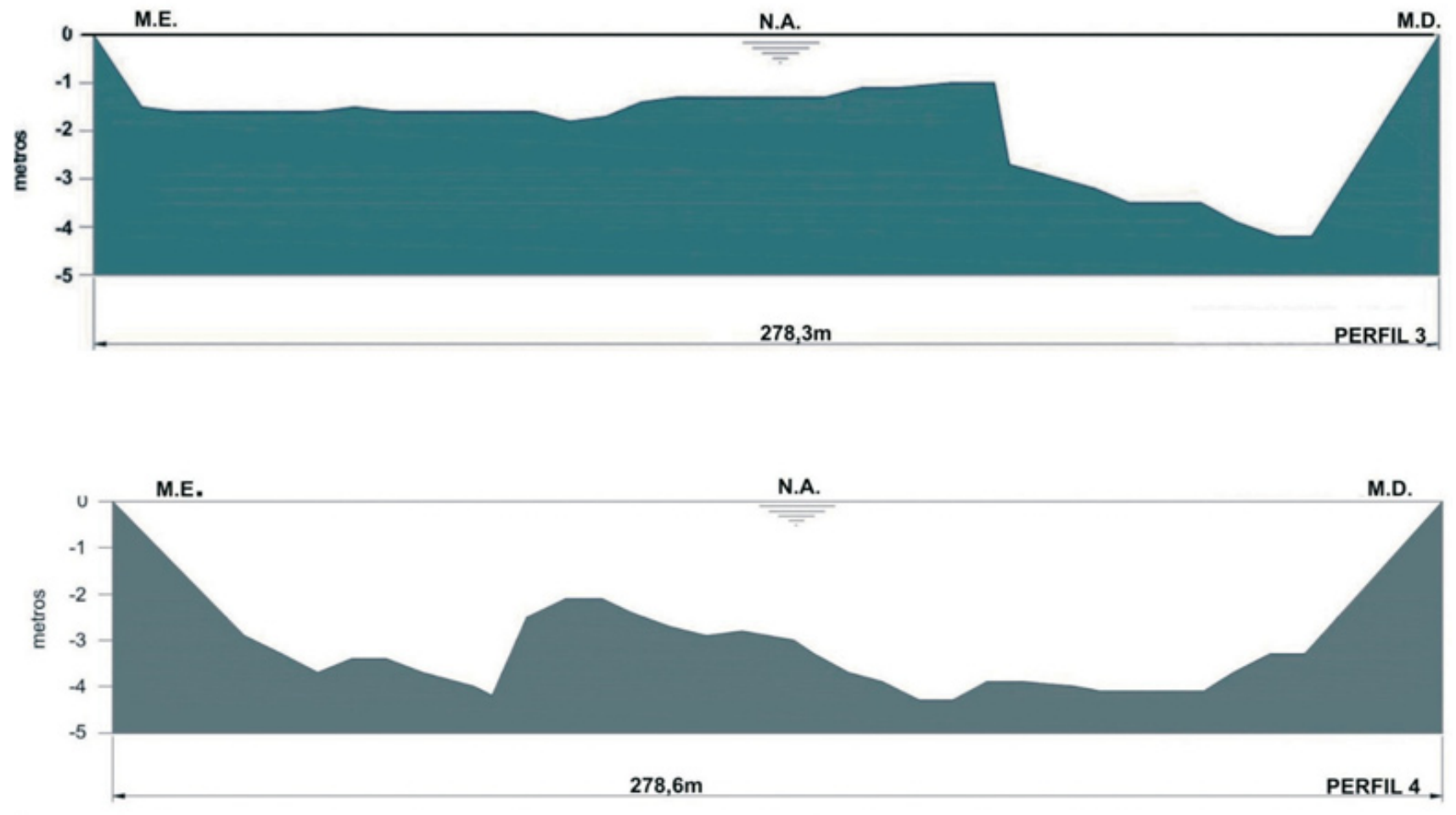

Figura 6 - Seções transversais do segmento inferior. O perfil 3 está situado a $75 \mathrm{~km}$ de Cáceres, e possui L/P de 139,1. O perfil 4 está situado a 77,1 km da cidade, e possui L/P de 81,9.
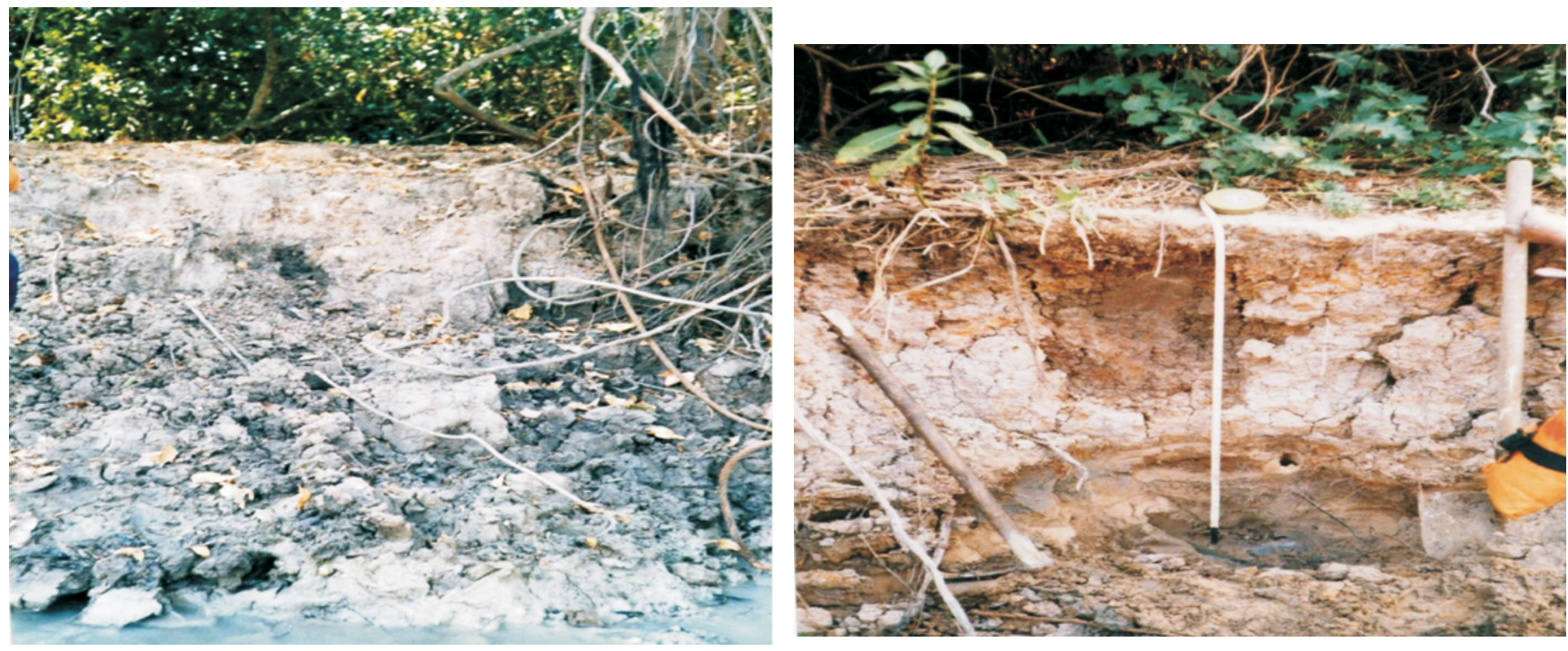

Figura 7 - Aspecto das margens do segmento inferior. À esquerda, observa-se argila siltosa cinza maciça, e à direita uma camada de argila arenosa na parte superior, com cerca de $40 \mathrm{~cm}$.

andrante, anastomosado e retilíneo) foram os adotados nesse trabalho.

O levantamento bibliográfico de dados de vários rios e de sínteses de diversos autores permitiu o levantamento de características morfológicas e dinâmicas dos quatro padrões mencionados, conforme exposto na tabela 1. A tabela serve como referência para a comparação dos dois segmentos do rio Paraguai Superior, cujos dados estão apresentados na tabela 2 .

Os dados obtidos para todo o intervalo fluvial estudado indicam que o sistema possui baixa energia, uma vez que o gradiente hidráulico máximo é de 9,6 $\mathrm{cm} / \mathrm{km}$, e a potência específica da corrente em margens plenas é de $2,2 \mathrm{~W} / \mathrm{m}^{2}$. As velocidades de fluxo de cada segmento individualizado confirmam as condições de baixa energia no sistema e indicam que apesar da exis- 
Tabela 1 - Características dos padrões de canais deposicionais.

\begin{tabular}{|c|c|c|c|c|}
\hline & Entrelaçado & Meandrante & Retilíneo & Anastomosado \\
\hline Gradiente $(\mathrm{cm} / \mathrm{km})$ & 7 a 1800 & $\leq 500$ & $\leq 20$ & $\leq 15$ \\
\hline Potência espacífica $\left(\mathrm{W} / \mathrm{m}^{2}\right)$ & $50-300$ & $10-60$ & $\leq 10$ & $\leq 10$ \\
\hline Velocidade máxima $(\mathrm{m} / \mathrm{s})$ & 0,4 a 6,0 & $\leq 2,0$ & $\leq 1,5$ & $\leq 1,5$ \\
\hline Carga de fundo & Seixos e areia & Areia & Areia fina & Areia fina \\
\hline$\%$ de carga de fundo & $\geq 11$ & $\leq 11$ & $\leq 11$ & $\leq 3$ \\
\hline Tipo de canal & Múltiplo & Único & Único & Múltiplo \\
\hline Talvegue & Múltiplo & Único & Único & Único \\
\hline Mobilidade do talvegue & Alta & Alta & Baixa & Baixa \\
\hline Sinuosidade & $\leq 1,3$ & $\geq 1,3$ & $\leq 1,5$ & $\geq 2,0$ \\
\hline Proporção de finos na margem \% & $\leq 5$ & de 5 a 20 & $\geq 20$ & $\geq 20$ \\
\hline Tipo de margem & Indefinida & Definida & Definida & Definida \\
\hline Estabilidade & Baixa & Baixa & Alta & Alta \\
\hline Seção transversal & Simétrica & Assimétrica & Simétrica & Simétrica \\
\hline Largura/profundidade & $\geq 40$ & de 10 a 40 & $\leq 10$ & $\leq 10$ \\
\hline Tipos de barras & $\begin{array}{l}\text { Longitudinal, } \\
\text { transversal, } \\
\text { composta }\end{array}$ & $\begin{array}{l}\text { Em pontal, } \\
\text { Lateral }\end{array}$ & Lateral & Lateral \\
\hline Planície de inundação & Mal desenvolvida & $\begin{array}{c}\text { Bem } \\
\text { desenvolvida }\end{array}$ & $\begin{array}{c}\text { Muito bem } \\
\text { desenvolvida }\end{array}$ & $\begin{array}{c}\text { Muito bem } \\
\text { desenvolvida }\end{array}$ \\
\hline Formas na planície & Paleo-barras & $\begin{array}{c}\text { Meandro } \\
\text { Abandonado } \\
\text { "scroll bars" }\end{array}$ & Crevasses & $\begin{array}{c}\text { Lagoas } \\
\text { alongadas } \\
\text { e arredondadas } \\
\text { crevasses }\end{array}$ \\
\hline Diques marginais & $\begin{array}{l}\text { Ausentes, mal } \\
\text { desenvolvidos }\end{array}$ & Descontínuos & $\begin{array}{c}\text { Contínuos, } \\
\text { bem } \\
\text { desenvolvidos }\end{array}$ & $\begin{array}{l}\text { Contínuos, bem } \\
\text { desenvolvidos }\end{array}$ \\
\hline Composição dos diques & $\begin{array}{c}\text { Arenosos, } \\
\text { não coesivos }\end{array}$ & $\begin{array}{c}\text { Areno- } \\
\text { argilosos, } \\
\text { não coesivos }\end{array}$ & $\begin{array}{l}\text { Argilosos, } \\
\text { coesivos }\end{array}$ & $\begin{array}{l}\text { Argilosos, } \\
\text { coesivos }\end{array}$ \\
\hline
\end{tabular}

Fonte - Miall (1977), Richards (1982), Nanson e Crooke (1992), Souza Filho (1993).

tência de níveis de base locais, não há diferença significativa entre o trecho fluvial superior e o inferior. Contudo, as informações de 1982 sobre o transporte fluvial em Cáceres, a textura dos sedimentos de fundo, a razão largura/profundidade, a presença de barras transversais e de talvegues múltiplos são indicativos de canais de alta energia (padrão entrelaçado). A aparente contradição entre as condições de energia e de transporte pode ser indicativa de um aporte excessivo de material arenoso no sistema, e um conseqüente desequilíbrio deste.

Os dados relativos ao segmento entre Cáceres e a foz do rio Jauru mostram que a planície fluvial nesse intervalo foi formada por um rio meandrante, e que parte das características do canal (tipo, sinuosidade, a seção transversal nos meandros, as barras em pontal, a mobilidade e a textura da carga de fundo) são compatíveis com tal padrão. Contudo, a velocidade de fluxo pode indicar condições de energia mais baixas, e por outro lado, a existência de barras transversais, de talvegue múltiplo nos trechos retos, e a razão largura/profundidade indicam características de rios entrelaçados. A planície fluvial do referido segmento deve ter 
Tabela 2 - Características dinâmicas e morfológicas dos segmentos fluviais estudados.

\begin{tabular}{|c|c|c|}
\hline & Segmento superior & Segmento inferior \\
\hline Gradiente do leito $(\mathrm{cm} / \mathrm{km})$ & 6,6 & \\
\hline Gradiente hidráulico máximo $(\mathrm{cm} / \mathrm{km})$ & 9,6 & \\
\hline Potência específica $\left(\mathrm{W} / \mathrm{m}^{2}\right)$ & 2,2 & \\
\hline Vel. média (margens plenas) $(\mathrm{m} / \mathrm{s})$ & 0,5 & 0,6 \\
\hline Vel. Máxima (superfície) $(\mathrm{m} / \mathrm{s})$ & 1,2 & 1,2 \\
\hline Carga de fundo & Areia média & Areia média (grossa) \\
\hline Proporção de carga de fundo (\%) & 19,2 & \\
\hline Tipo de canal & Único & Único, raras ilhas \\
\hline Talvegue & Único/múltiplo & Múltiplo \\
\hline Mobilidade & Alta & Alta \\
\hline Sinuosidade & 1,7 & 1,2 \\
\hline Composição das margens & Areia fina e argila & Argilosa \\
\hline Tipo de margem & Definida & Definida \\
\hline Estabilidade (1984 a 2003 - m/ano) & 2,5 & 1,9 \\
\hline Seção transversal & Assimétrica e simétrica & Simétrica \\
\hline Largura/profundidade & 35,2 a 210,4 & 81,9 a 270,7 \\
\hline Tipos de barras & Pontal e transversais & Transversais \\
\hline Planície de inundação & Bem desenvolvida & Bem desenvolvida \\
\hline Formas na planície & $\begin{array}{l}\text { Meandros abandonados, } \\
\text { avulsões, "scroll bars" }\end{array}$ & $\begin{array}{l}\text { Lagoas alongadas e } \\
\text { "crevasses" }\end{array}$ \\
\hline Diques marginais & $\begin{array}{l}\text { Pouco desenvolvido, } \\
\text { descontínuo }\end{array}$ & Ausente \\
\hline Composição dos diques marginais & Areia fina & \\
\hline
\end{tabular}

sido formada por um canal tipicamente meandrante, e as condições de energia indicam que o canal tendia para um padrão anastomosado. Contudo, em determinado momento, o aporte excessivo de areia pode ter desequilibrado o sistema e iniciado um processo de ajuste.

$\mathrm{O}$ segmento fluvial situado entre a foz do rio Jauru e o Morro Pelado apresenta canal característico de rios retilíneos, mas a planície mostra feições de sistemas anastomosados, com exceção feita à ausência de diques marginais bem desenvolvidos e contínuos. A hidrodinâmica e as margens definidas e argilosas são compatíveis com ambos os padrões mencionados. Contudo, a granulação da carga de fundo, o canal único e móvel, o talvegue múltiplo e móvel, a elevada razão largura/profundidade e as barras transversais são próprios de rios entrelaçados.

O conjunto canal-planície indica desajuste entre o atual (canal) e o antigo (planície). A planície deve ter sido construída por um rio anastomosado, hoje descaracterizado pelo canal ativo, que inclusive deve ter removido os diques marginais antigos. Entretanto, a seqüência de eventos que levou ao quadro atual ainda necessita de estudo. Há pelo menos duas possibilidades a serem consideradas: a primeira é que o sistema evoluiu de anastomosado para retilíneo forçado por basculamento da planície (o canal ocupa a margem oriental da calha) e depois foi alterado pelo aporte de areia; a segunda é que o sistema passou diretamente de anastomosado para entrelaçado e o basculamento da planície foi responsável pela ativação do canal situado mais a leste da calha.

A passagem de um sistema anastomosado para um entrelaçado foi descrita no rio Paraná por Souza Filho (1993), e o autor atribuiu a mudança à troca climática de condições mais secas para mais úmidas. $\mathrm{O}$ 
aumento de descarga fluvial teria sido responsável pelo aumento de energia do sistema, e proporcionado um recuo do nível de base (salto de Sete Quedas). Tal recuo teria diminuído o tamanho do segmento situado à montante, provocando um aumento do gradiente do canal.

A diferença fundamental entre ambos os casos é que no rio Paraná o canal ainda é dividido por grandes arquipélagos cujas ilhas foram construídas no padrão anterior. No rio Paraguai, o canal teria que ter removido quase todas as ilhas, o que parece improvável face à baixa energia do sistema.

A observação das características de ambos os segmentos do rio Paraguai Superior demonstra que a passagem entre os diversos padrões de canal é abrupta. A norte do rio Jauru, a planície fluvial mostra feições de depósitos de rios meandrantes, e a sul as feições são de depósitos de rios anastomosados. Da mesma forma, o canal ativo muda de sinuosidade exatamente na foz do rio Jauru.

Tal situação pode ser observada em todo o rio Paraguai Superior. A porção mais alta é claramente constituída por canais erosivos, e tal condição é interrompida sem transição na foz do ribeirão dos Bugres, quando a planície fluvial tem início. A parte da planície situada mais a montante possui feições indicativas de canais anastomosados, que cessam de ocorrer a partir da foz do rio Cabaçal (situado pouco a montante de Cáceres), e cedem lugar às feições típicas de canais meandrantes, no segmento situado entre Cáceres e a foz do rio Jauru. A partir daí, a planície é marcada pelas feições típicas de canais anastomosados, que persistem até a Estação de Caimã, já no domínio do Pantanal Mato-Grossense.

O canal ativo também mostra modificações bruscas nos mesmos locais, ou seja, ele passa de canal único e erosivo para canal múltiplo separado por grandes ilhas, em seguida para canal único com alta sinuosidade, e por fim passa a apresentar baixa declividade. No segmento que corre no Pantanal, o rio exibe tanto canal simples como múltiplo, sempre com alta sinuosidade.

Ambas as situações demonstram que o rio $\mathrm{Pa}-$ raguai Superior desenvolveu sua planície sobre blocos tectônicos cuja movimentação condicionou o gradiente de cada segmento, e que essa influência ainda persiste, conforme demonstrado por Souza Filho \& Silva (2005).

A presente disposição dos compartimentos identificados na planície do rio Paraguai, da foz do rio Sepotuba à extremidade leste da ilha Taiamã, representa um momento na evolução do sistema. As tendências de mudança são condicionadas pela dinâmica interna que caracteriza o funcionamento do próprio sistema (processos autogênicos) e por variáveis externas do macroambiente no qual o sistema está inserido (processos alogênicos relacionados à tectônica e ao clima) (Silva et al., 2007).

CONCLUSÃO O rio Paraguai Superior, no intervalo entre Cáceres e o morro Pelado, possui hidrodinâmica compatível com a dos padrões retilíneo e anastomosa- do, mas a carga sedimentar é típica de rios entrelaçados. A morfologia da planície e do canal ativo permite a distinção de dois segmentos distintos.

O segmento superior (situado entre proximidades de Cáceres até a foz do rio Jauru) possui planície com morfologia típica das áreas de inundação de canais meandrantes e parte das características morfológicas indicativas do mesmo padrão de canal (tipo do canal, sinuosidade, seção transversal nos meandros, barras em pontal). Contudo, há uma parte das características morfológicas que são mais próprias de um padrão entrelaçado (razão largura/profundidade, presença de barras transversais, e talvegue múltiplo). A velocidade de fluxo, por sua vez, é indicativa de padrão de canal de baixa energia (anastomosado ou retilíneo).

O segmento inferior possui planície com formas típicas das áreas de inundação de canais anastomosados, hidrodinâmica de rios de baixa energia, mas alguns aspectos do canal são típicos de sistemas retilíneos (tipo do canal, margens argilosas e bem definidas), enquanto outros são próprios de rios entrelaçados (carga de fundo, talvegue múltiplo, barras transversais, razão largura/profundidade).

A co-existência de características de diferentes padrões de canal indica que o sistema encontra-se em processo de ajuste, e o tempo transcorrido a partir da ruptura do equilíbrio inicial não foi suficiente para que as novas condições tenham sido implantadas de forma definitiva. A ruptura do equilíbrio do sistema aparentemente foi causada pelo aporte excessivo de areia, cuja origem pode ser conseqüência de mudança climática ou da ocupação da bacia, ou ainda ter participação de ambos os fatores. A implantação do clima atual pode ter aumentado o escoamento superficial e o aporte de sedimentos antes que a vegetação equilibrasse o sistema, e a retirada da vegetação para a ocupação da bacia deve ter causado efeito similar, visto que Silva (2005) relatou um aumento da concentração de carga suspensa no período compreendido entre as décadas 1960 e 1980. A ocupação das vertentes é recente demais para ser responsável pelo fenômeno, mas certamente contribui para sua intensificação.

Os padrões descritos mostram passagem brusca, e a mesma situação pode ser observada em todo o rio Paraguai Superior. Tal situação indica que o rio é controlado por movimentos diferenciais de blocos tectônicos definidos por uma linha estrutural paralela à calha do rio e por linhas transversais ocupadas pelos afluentes. Uma vez que a influência tectônica é evidente no que diz respeito à compartimentação dos diferentes padrões, e que há indícios de movimentação recente, é provável que ela também tenha participado da ruptura do equilíbrio do sistema, mas ainda não há evidências claras a respeito.

Agradecimentos Os autores agradecem ao $\mathrm{CNPq}$ pela concessão de bolsas de produtividade em pesquisa (EESF, SBC), de doutorado (AS) e a FAPESP processo 07/55987-3. 


\section{Referências}

Almeida F.F.M. de. 1964. Geologia do Centro-Oeste MatoGrossense. Boletim da divisão de Geologia e Mineralogia, Rio de Janeiro, 117, p. 1-11.

Alvarenga C.J.S. \& Trompette R. (1993). Evolução Tectônica Brasiliana da Faixa Paraguai: A estruturação da região de Cuiabá. Revista Brasileira de Geociências, 23(1):18-30.

AGÊNCIA NACIONAL DE ÁGUAS (ANA). 2004. Implementação de Práticas de Gerenciamento Integrado de Bacia Hidrográfica para o Pantanal e Bacia do Alto Paraguai: Programa de Ações Estratégicas para o Gerenciamento Integrado do Pantanal e Bacia do Alto Paraguai. Brasília, ANA/GEF/PNUMA/OEA, Relatório Final (Disponível em CDRom, no endereço http://www.ana.gov.br/AcoesAdministrativas/CDOC/ CatalogoPublicacoes_2004.asp).

Collinson J.D. 1986. Alluvial sediments. In: Reading H.G. (ed.) Sedimentary Environment and Facies. Oxfordp, Blackwell Scientific, p.20-62.

Dietrich W.E. 1985. Mechanics of flow and sediment transport in river bends. In: Petts G. (ed.) Rivers a landscape. Blackwell, Oxford, Edward Arnold, p. 158-174.

DNOS 1974. Estudos Hidrológicos da Bacia do Alto Paraguai. Rio de Janeiro, Programa das Nações Unidas para Desenvolvimento, Relatório Técnico, p. 284 (disponível nas bibliotecas da Unesp, USP, UFMS).

Fisk H.M. 1944. Geological investigation of the alluvial valley of the lower Mississippi River. U.S. Department of Army . Mississippi Commission, 78p.

Fisk H.M. 1947. Fine grained alluvial deposits and their effect on Mississippi River activit. U.S. Department of Army, Mississippi Commission, 78 p.

Friedman G.H., Sanders J.E. 1978. Principles of Sedimentology. New York, John Willey e Sons, 792 p.

INSTITUTO BRASILEIRO DE GEOGRAFIA E ESTATÍSTICA (IBGE). 1977. Geografia do Brasil. Rio de Janeiro, vol. 4, Região Centro-Oeste, p. 85-112.

Innocencio N.R. 1977. Hidrografia. In: IBGE (ed.) Geografia do Brasil. Rio de Janeiro, IBGE, vol. 1 (Região CentroOeste), p. 73-90.

Kellerhald R., Church M., Bray D. 1976. Classification and analysis of river processes. American society of Civil Engineers Proceeding. Journal of the Hydraulics Division, 102:813-829.

Leopold L.B. \& Wolman M.G. 1957. River channel patterns: braided, meandering, and straight. US Geol. Survey. Prof. Paper., 282-B.

Miall A.D. 1977. A Review of the Braided-River Depositional Environment. Earth Science Reviews, 13(1):1-62.

Miall A.D. 1978. Lithofacies types and vertical profile models in braided river deposits: a summary. In: Miall A.D. (ed.) Fluvial Sedimentology. Canadian Society of Petroleum Geologists, 597-604 (memoirs).

Miall A.D. 1985. Architectural element analysis: a new method of facies analysis applied to fluvial deposits. Earth Science Reviews, 22:261-308.

Nanson G.C. \& Crooke J.C. 1992. A Genetic Classification of Floodplains. Geomorphology, 4(6):459-486.

PCBAP. 1997. Plano de Conservação da Bacia do Alto Paraguai-Pantanal. Brasília: Diagnóstico do Meio Físico e Biótico. Ministério dos Recursos Hídricos e da Amazônia Legal Vol. 2, p. 1349.

BRASIL. Ministério das Minas e Energia. 1982. Folha SE.21 Cuiabá e parte da Folha SE.20: geologia, geomorfologia, vegetação e uso potencial da terra. Projeto RADAMBRASIL. Rio de Janeiro. Projeto Folha SD 21 Cuiabá. (Levantamentos dos recursos naturais, 27), p. 448.

Richards K. 1982. Rivers. Forms and processes in alluvial channels. New York, Methuen e Co., 358 p.

Selley R.C. 1978. Ancient sedimentary environments. New York, Cornell Univ. Press, p. 39.

Silva A. 2006. Padrões de Canal do rio Paraguai na região de Cáceres - MT. Dissertação de Mestrado, Universidade Estadual de Maringá, 80p.

Silva A., Assine M.L., Zani H., Souza Filho E.E. de, Araújo B.C. 2007. Compartimentação Geomorfológica do rio Paraguai na borda norte do Pantanal Mato-Grossense, região de Cáceres-MT. Revista Brasileira de Cartografia, 59(1):73-81.

Souza Filho E.E. \& Silva A. 2005. Evidences of recent tectonic control over high Paraguai River channel, close Cáceres City (MT). In: International Symposium on Land Degradation and Desertification, Uberlândia, $A b$ stracts, p. 37.

Souza C.A. 2004. Dinâmica do Corredor Fluvial do rio Paraguai entre a cidade de Cáceres e a Estação Ecológica da Ilha de Taimã - MT. Tese de Doutoramento, Universidade Federal do Rio de Janeiro, 174p.

Souza Filho E.E. 1993. Aspectos da Geologia e Estratigrafia dos Depósitos Sedimentares do Rio Paraná entre Porto Primavera (MS) e Guaíra (PR). Tese de Doutoramento, Instituto de Geociências/USP, São Paulo, 180p.

Walker R.G. \& Cant D.J. 1979. Sandy fluvial systems. In: Walker R.G. (ed.) Facies models. Second Edition. Ontario, Geocience, Canada reprint series 1, p. 71-90.

Manuscrito ID 8255

Submetido em 04 de julho de 2007

Aceito em 20 de junho de 2008 Sistema eletrônico de submissão 